\title{
OPTIMASI PROSES POLIMERISASI CNSL DENGAN FORMALDEHID UNTUK APLIKASI COATING FURNITURE
}

\author{
Faleh Setia Budi (1) dan Luqman Buchori $(1,2)$ \\ (1) Departemen IImu dan Teknologi Pangan, Fakultas Teknologi Pertanian IPB Bogor \\ E-mail : faleh sb01@yahoo.com \\ (2) Jurusan Teknīk Kimia Fakultas Teknik Universitas Diponegoro Semarang \\ JI. Prof. Soedharto, SH, Tembalang - Semarang; Telp. (024)7460058; fax. (024)76480675 \\ E-mail : lugmanbuchori@undip.ac.id
}

\begin{abstract}
ABSTRAK
Produksi jambu mete Indonesia mengalami peningkatan sebesar 6,2\% dari tahun 1999 sampai 2003. Selain menghasilkan produk utama kacang mete yang bernilai ekonomi tinggi proses pemecahan biji mete juga menghasilkan limbah kulit biji yang belum dimanfaatkan secara optimal. Kulit biji mete mengandung minyak (Cashew Nut Shell Liquid/CNSL) sekitar 32-36\%. Minyak ini mengandung senyawa phenol sehingga dapat dimanfaatkan sebagai sumber phenol alami dalam pembuatan resin phenol formaldehid, menggantikan phenol yang berasal dari minyak bumi yang cadangannya semakin menipis. Penelitian yang dilakukan bertujuan untuk mengetahui pengaruh variabel perbandingan reaktan dan suhu operasi terhadap resin yang dihasilkan dan mencari kondisi optimum reaksi polimerisasi phenol formaldehid dari CNSL serta kualitas coating yang dihasilkan. Pada proses reaksi phenol formaldehid variabel yang dipilih sebagai variabel berubah adalah rasio Formaldehid/CNSL atau F/C (0.5, 0.75 dan 1) dan suhu operasi $\left(70,80\right.$ dan $\left.80^{\circ} \mathrm{C}\right)$. Sedangkan lainnya merupakan variabel tetap yang meliputi volume $250 \mathrm{ml}$, katalis $\mathrm{HCl}_{(\mathrm{p})}=4 \mathrm{ml}$, kecepatan pengadukan $200 \mathrm{rpm}$, waktu operasi 90 menit, $\mathrm{pH}=2$ dan tekanan operasi $1 \mathrm{~atm}$. Parameter yang diamati adalah kadar formaldehid bebas. Metode yang digunakan untuk merancang dan mengolah data hasil percobaan adalah RSM (Respon Surface Methodology). Variabel yang paling berpengaruh adalah rasio $\mathrm{F} / \mathrm{C}$ dan kondisi optimum didapatkan pada rentang rasio $F / C=0,65-0,85$ dan rentang suhu $75-85^{\circ} \mathrm{C}$ dengan konversi 0,55 . Kualitas resin terbaik untuk aplikasi coating diper oleh pada perbandingan reaktan $\mathrm{F} / \mathrm{C}=0,75 / 1$.
\end{abstract}

Kata Kunci: CNSL; pelapisan; phenol formaldehid

\begin{abstract}
The cashew fruit production of Indonesia increased $6.2 \%$ from 1999 to 2003. In addition the main product of cashew nut which had high economic value the processing of cashew nut also produced the waste of nut shell that had not been used optimally. The cashew nut shell contains the oil which called The Cashew Nut Shell Liquid (CNSL) about 32-36 \%. These have phenol compound so that can be used as material in manufacturing of phenol formaldehid resin, replace the synthetic phenol from petroleum. This research aims to study the effect of formaldehid/CNSL ratio and temperature on the producted resin and to get the optimal condition of polymerization reaction of phenol formaldehid as well as the coating quality of the obtained resin. The variable choose as the independent variable were Formaldehid/ CNSL ratio $(0.5 ; 0.75$ and 1$)$ and the temperature $\left(70 ; 80\right.$ and $\left.90{ }^{\circ} \mathrm{C}\right)$. The others were the fixed variable which include volume $250 \mathrm{~mL}$, catalyst $(\mathrm{HCl}) 4 \mathrm{~mL}$, the agitation speed $200 \mathrm{rpm}$, time 90 minute, pH 2 and pressusre $1 \mathrm{~atm}$. The parameter observed was the free formaldehid content. The method used to design the experiment and to calculate the data of experiment was Response Surface Methodology (RSM). The most affected variable was the Formaldehid/ CNSL ratio. The optimal reaction condition was achieved at Formaldehid/CNSL ratio 0.65-0.85 and the temperature 75-85 oC with the conversion 0.55 . The good quality of resin for coating application was reached at Formaldehid/ CNSL ratio 0.75/ 1.
\end{abstract}

Keywords: CNSL; coating; phenol formaldehide 


\section{PENDAHULUAN}

Resin Phenol Formaldehid merupakan resin yang dibuat dengan cara mereaksikan phenol dengan formaldehid dan mempunyai berbagai macam kegunaan antara lain: sebagai lak dan vernish, senyawa cetakan, bahan laminating, plastik dan bahan perekat. Selama ini phenol yang digunakan sebagai bahan baku dalam pembuatan resin phenol forlmaldehid berasal dari minyak bumi (Heese, 1991). Minyak bumi merupakan sumber daya alam yang tidak terbarukan dan cadangannya semakin menipis. Oleh karena itu, perlu dicarikan bahan alternatif untuk menggantikan sumber phenol lain selain minyak bumi.

Sejak pertengahan tahun 1972 jambu mete telah dicanangkan pemerintah sebagai salah satu tanaman ekspor yang mempunyai peran ganda yaitu dalam rangka meningkatkan pendapatan petani, memperluas lapangan kerja serta kesempatan berusaha, penghijauan dan memulihkan kembali kondisi tanah kritis. Berdasarkan data dari Dirjen Perkebunan, produksi jambu mete dari tahun 1999-2003 mengalami peningkatan yang cukup signfikan (dari 89.500 ton menjadi 118.300 ton) (BPS, 2003). Biji mete atau kacang mete yang merupakan produk utama dari tanaman jambu mete mempunyai nilai ekonomi tinggi (harga mahal) dan sangat dikenal oleh masyarakat sebagai makanan ringan lezat maupun untuk campuran kue, coklat dan lain-lain. Buah mete semu dapat diolah menjadi beberapa bentuk olahan seperti sari buah mete, anggur mete, manisan kering, selai mete, buah kalengan dan jam/ selai jambu mete (Daru dan Nunung, 1994).

Kulit biji mete yang merupakan hasil samping dari proses pemecahan biji mete untuk mengambil kacang mete belum dimanfaatkan secara optimal dan menjadi limbah pada industri kacang mete. Di Kabupaten Jepara (Kepulauan Karimunjawa) limbah kacang mete ini digunakan sebagai bahan isian tanah/urug (landfill) dan kayu bakar. Penggunaan limbah kacang mete sebagai bahan isian tanah dapat merusak lingkungan karena senyawa kimia yang terdapat dalam limbah kulit kacang mete dapat membunuh mikroorganisme tanah. Senyawa kimia tersebut juga berbahaya terhadap manusia karena dapat menyebabkan iritasi pada kulit.

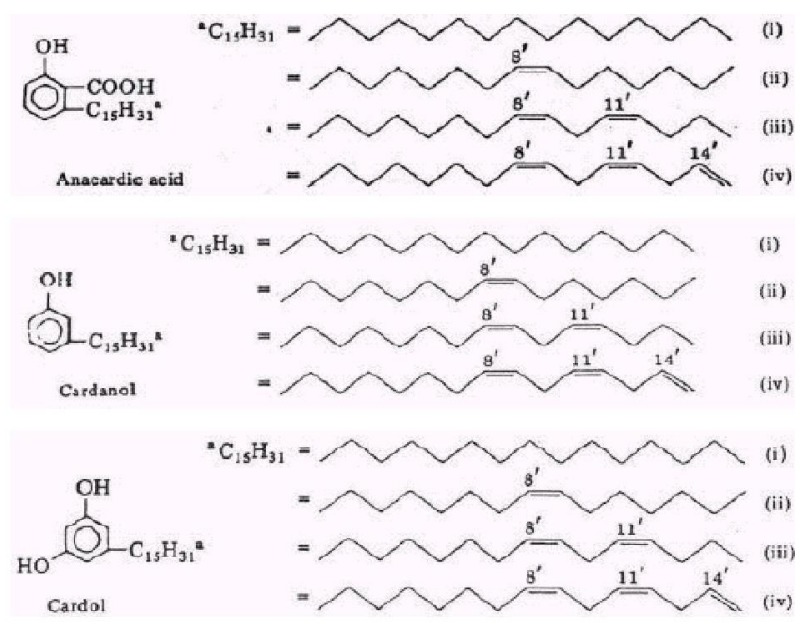

Gambar 1. Senyawa kimia minyak jambu mete dan struktur molekulnya

Sebenarnya kulit biji mete mengandung minyak yang disebut Minyak Kulit Biji Mete (MKBM)/Cashew Nut Shell Liquid (CNSL). Kandungan CNSL dalam kulit biji mete sekitar 32$36 \%$. Komponen-komponen yang terdapat dalam CNSL terdiri dari Asam Anarkadat, Kardol dan Kardanol dengan komposisi masing-masing 70\%, 18\% dan 5\% (Budiati dkk., 2004). Asam Anarkadat, Kardol dan Kardanol merupakan senyawa kimia alami yang mengandung gugus phenol. Oleh karena itu Minyak Kulit Biji Mete mempunyai potensi untuk digunakan sebagai bahan baku dalam pembuatan resin phenol formaldehid. Namun senyawa phenol dari Minyak Kulit Biji Mete (Asam Anarkadat, Kardanol dan Kardol) juga memiliki gugus-gugus lain seperti gugus karboksilat, gugus alkil dan gugus alkena. Gugus itu tentunya akan mempengaruhi proses reaksi pembentukan resin phenol formaldehid dan karakteristik serta kualitas resin phenol formaldehid yang dihasilkan sehingga perlu dicari kondisi optimum dalam pembuatan resin phenol formaldehid dan formulasi aplikasinya. Penelitian yang dilakukan bertujuan untuk mengetahui pengaruh variabel perbandingan reaktan dan suhu operasi terhadap resin yang dihasilkan dan mencari kondisi optimum reaksi polimerisasi phenol formaldehid dari CNSL serta kualitas coating yang dihasilkan.

Phenol formaldehid dihasilkan dari reaksi polimerisasi antara phenol dan formaldehid, di mana formaldehid mempunyai fungsionalitas 2 dan phenol mempunyai fungsionalitas 3. Reaksi terjadi antara phenol pada posisi ortho maupun para dengan formaldehid untuk membentuk rantai yang crosslinking dan pada akhirnya akan 
membentuk jaringan tiga dimensi (Hesse, 1991). Ada banyak faktor yang mempengaruhi karakteristik produk Phenol formaldehid dan dua di antaranya adalah jenis katalis (asam/ basa) dan rasio phenol/ formaldehid (lebih atau kurang dari 1) sehingga phenol formaldehid yang dihasilkan dibagi menjadi 2 jenis yakni resole dan novolac.

Novolac merupakan hasil reaksi antara satu mol phenol dengan kurang dari satu mol phenol formaldehid oleh adanya katalis asam. Jenis katalis asam yang sering digunakan adalah asam sulfat, asam klorida, dan asam oksalat dengan range $\mathrm{pH}=1-2$. Oleh karena rasio formaldehid/phenol kurang dari satu maka produk yang terbentuk bersifat termoplast dengan berat molekul 500-900. Novolac thermoplast bisa diubah sifatnya menjadi termoset dengan melakukan pemanasan dan penambahan crosslinking agent seperti donor formaldehid (ex: urea formaldehid) maupun hexamethylenetetramine. Novolac disebut juga two step resin karena tidak bisa cure dengan sendirinya (Frisch, 1967).

Novolak mempunyai sifat mudah larut dalam pelarut dan permanen jika pelarut tersebut diuapkan. Novolak merupakan resin phenol formaldehid (PF) yang bersifat thermoplas. Novolak terbentuk apabila suasana asam. Pembentukan gugus metylol berjalan lambat, sedangkan terurainya metylol menjadi gugus rantai metylene dan pembentukan ether berjalan cepat. Struktur molekul novolak sebagai berikut:

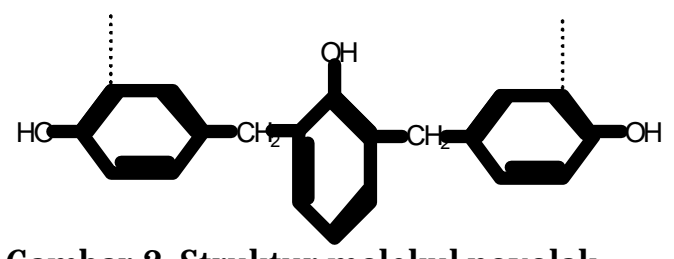

Gambar 2. Struktur molekul novolak

\section{METODE PENELITIAN}

Penelitian pembuatan resin phenol formaldehid ini menggunakan minyak kulit biji mete (CNSL) yang diperoleh dengan mengepres kulit biji mete di Laboratorium. Kulit biji mete tersebut didapatkan dari industri rumah tangga kacang mete di daerah Kabupaten Wonogiri dan merupakan limbah. Formaldehid yang digunakan adalah formaldehid teknis yang dibeli dari C.V. Multi Kimia Raya. Katalis HCl dan pelarut alkohol dibeli dari toko kimia Brataco.

Peralatan yang dipakai terdiri dari reaktor polimerisasi, pengaduk, motor pengaduk, pemanas, termometer, termokontrol, termokopel dan pendingin balik. Alat-alat tersebut dirangkai seperti pada Gambar 3.

Metode optimasi berdasarkan metode permukaan respon (RSM) melibatkan 3 langkah utama yaitu: rancangan percobaan yang menggunakan pendekatan statistik, estimasi koefisian model matematik dan prediksi respon dan terakhir pencocokan model. Model persamaan diuji dengan analisa varian (ANOVA) dengan derajat kepercayaan 99\%. Keluaran RSM seperti grafik permukaan kontur dan 3 dimensi memberikan kondisi operasi optimum dan variabel yang paling berpengaruh.

Percobaan dirancang dengan metode central composite design dengan dua variabel bebas/berubah. Variabel yang dipilih sebagai variabel bbas adalah rasio Formaldehid/ CNSL atau F/ C (level bawah : 0,5, level tengah : 0,75 dan level atas : 1) dan suhu operasi (level bawah: $70^{\circ} \mathrm{C}$, level tengah : $80^{\circ} \mathrm{C}$ dan level atas: $80^{\circ} \mathrm{C}$ ). Sedangkan lainnya merupakan variabel tetap yang meliputi volume $250 \mathrm{ml}$, katalis $\mathrm{HCl}_{(\mathrm{p})}=4 \mathrm{ml}$, kecepatan pengadukan $200 \mathrm{rpm}$, waktu operasi 90 menit, $\mathrm{pH}$ $=2$ dan tekanan operasi 1 atm. Parameter yang diamati adalah kadar formaldehid bebas. Jumlah run percobaan yang harus dilakukan dihitung dengan persamaan 1 .

$$
\Sigma \mathrm{R}=2^{\mathrm{k}}+2 \mathrm{k}+\mathrm{n}_{0}
$$

Di mana $R=$ jumlah run percobaan

$\mathrm{k}=$ jumlah variabel bebas

no = jumlah ulangan pada titik tengah.

Pada penelitian ini jumlah variabel bebasnya adalah dua (suhu dan rasio $\mathrm{F} / \mathrm{C}$ ) dan jumlah ulangan titik tengah ditentukan 2 sehingga jumlah percobaan yang harus dilakukan sebanyak 10 (Montgomery, 2001).

Percobaan terdiri dari tiga tahap yaitu pengambilan CNSL dari kulit biji mete, pembuatan resin phenol formaldehid dari CNSL dan aplikasi resin phenol formaldehid sebagai coating/ varnish.

Pada tahap pengambilan CNSL dari kulit biji mete, kulit biji mete disangrai sampai panas, ditimbang beratnya dan kemudian dimasukkan kedalam alat press untuk dilakukan pengepresan, ambil minyak yang keluar dari bagian bawah alat press lalu ukur volumenya.

Setelah itu dilakukan pembuatan resin phenol formaldehid. Masukan CNSL ke dalam labu leher tiga yang telah dirangkai seperti gambar 3 . Tambahkan $\mathrm{HCl}$ sampai $\mathrm{pH}$ campuran sama dengan 2. Lakukan pemanasan sampai suhu yang telah ditentukan dan juga lakukan pengadukan pada kecepatan tertentu. Masukkan formaldehid kedalam reaktor sesuai dengan perbandingan yang telah ditentukan. Setelah waktu reaksi polimerisasi 
tercapai, ambil sampel untuk dianalisa kadar formaldehid bebasnya.

Pada tahap aplikasi sebagai coating, sampel dipanaskan sampai meleleh, kemudian ditambahkan curing agent urea formaldehid dan dilarutkan dengan ethanol untuk dijadikan varrnish. Varnish yang diperoleh dioleskan ke bidang kayu untuk diamati hasil coating.

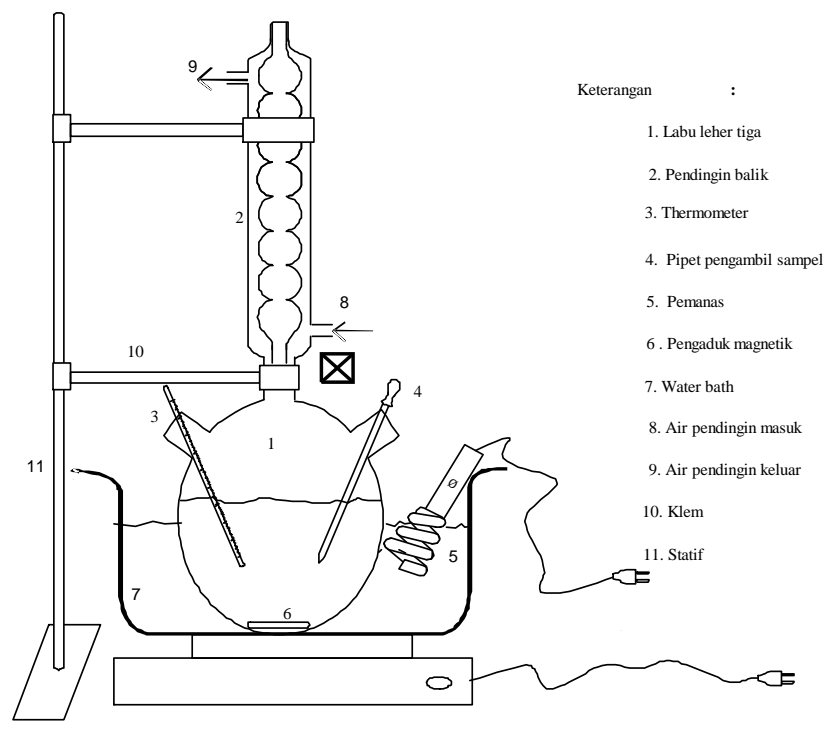

Gambar 3. Rangkaian alat percobaan

\section{HASI L DAN PEMBAHASAN}

Tabel 1. Konversi pada masing-masing variabel

\begin{tabular}{ccc}
\hline Rasio C/F & Suhu $\left({ }^{\circ} \mathrm{C}\right)$ & Konversi \\
\hline $1: 0,500$ & 70,00 & 0,33 \\
$1: 0,500$ & 90,00 & 0,11 \\
$1: 1,000$ & 70,00 & 0,19 \\
$1: 1,000$ & 90,00 & 0,26 \\
$1: 0,396$ & 80,00 & 0,21 \\
$1: 1,103$ & 80,00 & 0,06 \\
$1: 0,750$ & 65,85 & 0,10 \\
$1: 0,750$ & 94,14 & 0,53 \\
$1: 0,700$ & 80,00 & 0,55 \\
$1: 0,750$ & 80,00 & 0,55 \\
\hline
\end{tabular}

Data yang diperoleh diolah dengan perangkat lunak Statistica 6 untuk mendapatkan persamaan model matematik, grafik pareto untuk menentukan variabel yang paling berpengaruh dan grafik optimasi 3 dimensi untuk menentukan kondisi operasi optimum.

Persamaan model matematik yang diperoleh dituliskan pada persamaan 2 dan menyatakan hubungan empiris antara konversi dengan variabel percobaan dalam bentuk bilangan tak berdimensi yang diberi kode $\mathrm{x}_{1}$ dan $\mathrm{x}_{2}$, di mana $\mathrm{x}_{1}$ adalah variabel tak berdimensi dari rasio $\mathrm{F} / \mathrm{C}$ dan $\mathrm{x}_{2}$ adalah variabel tak berdimemsi dari suhu.

$\mathrm{Yu}=0.55-0.024805 \mathrm{x}_{1}+0.056481 \mathrm{x}_{2}-0.20606 \mathrm{x}_{1}^{2}-$

$0.11743 \mathrm{x}_{2}^{2}+0.072251 \mathrm{x}_{1} \mathrm{x}_{2}$

$\mathrm{x}_{1}=\mathrm{R}-0,75 / 0,5$

$\mathrm{x}_{2}=\mathrm{T}-80 / 20$

$\mathrm{R}$ : rasio $\mathrm{F} / \mathrm{C}$

$\mathrm{T}: \mathrm{Suhu}$

Pengaruh suhu dan rasio F/C terhadap konversi reaksi polimerisasi CNSL dan formaldehid dapat dianalisis dengan grafik pareto dengan tingkat kepercayaan $\mathrm{p}=0,05$ (Gambar 4).

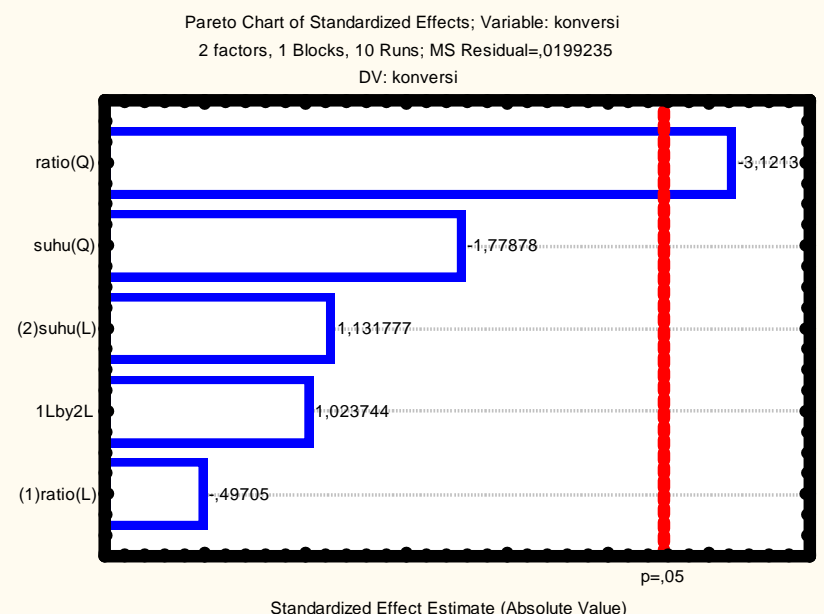

Gambar 4. Diagram Pareto

Gambar 4 menunjukkan bahwa variabel yang paling berpengaruh adalah rasio $\mathrm{F} / \mathrm{C}$ (kuadrat). Rasio akan mempengaruhi jumlah fungsionalitas pada masing-masing reaktan sehingga produk yang dihasilkanpun juga berbeda. Ketika rasio F/ C >1 maka pembentukan gugus methylol berjalan cepat daripada pembentukan jembatan methylene, sedangkan ketika rasio F/ C $<1$ maka pembentukan jembatan methylene berjalan cepat daripada pembentukan gugus methylol.

Gambar 5 dan Gambar 6 memperlihatkan bahwa konversi optimum (terbesar) terjadi rasio $\mathrm{F} / \mathrm{C}=0,65-0,85$ dan suhu $75-85^{\circ} \mathrm{C}$ dengan konversi 0,4-0,55. Grafik tersebut juga menunjukkan pengaruh rasio $\mathrm{F} / \mathrm{C}$ dan suhu secara simultan. Pada rentang rasio $\mathrm{F} / \mathrm{C}$ yang yang telah ditentukan, kenaikan suhu akan meningkatkan konversi reaksi. Kenaikan suhu akan meningkatkan gerakan molekul-molekul sehingga akan terjadi tumbukan antar molekul yang mengakibatkan terjadinya reaksi. Namun setelah mencapai suhu optimum $\left(80^{\circ} \mathrm{C}\right)$, kenaikan suhu akan menurunkan konversi reaksi. Formaldehid merupakan bahan kimia yang mudah menguap atau mempunyai titik didih yang 
rendah. Pada suhu di atas $80^{\circ} \mathrm{C}$, jumlah molekul formaldehid yang menguap semakin banyak dan molekul formaldehid yang terlarut dalam campuran reaksi semakin menurun sehingga berdampak pada menurunnya konversi reaksi. Dengan menurunnya konsentrasi, tumbukan antar molekul semakin berkurang.
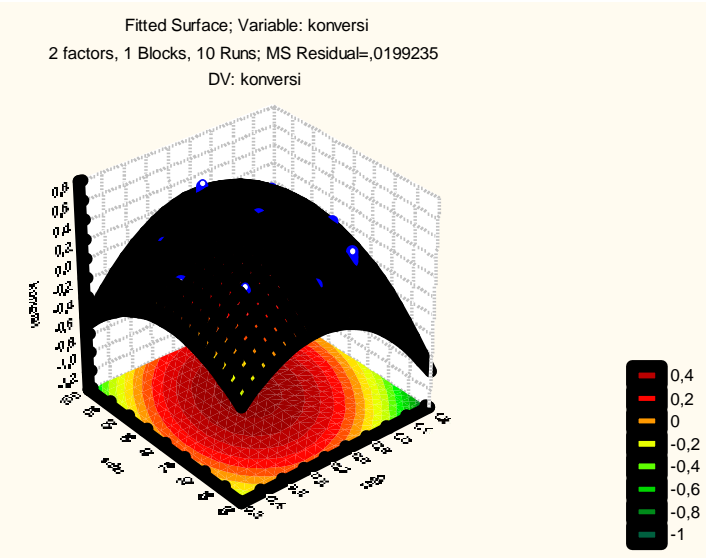

Gambar 5. Grafik optimasi 3 dimensi pengaruh suhu dan rasio Formaldehid/ CNSL (F/ C) terhadap konversi

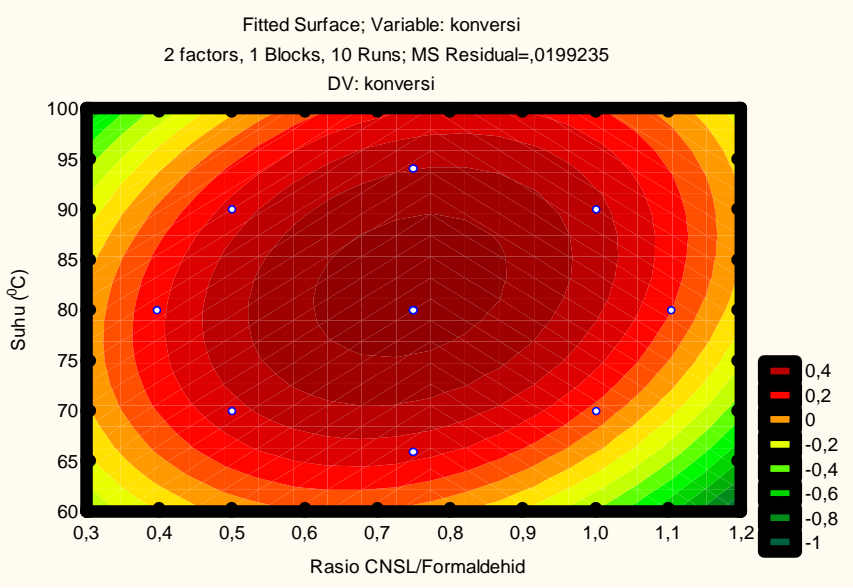

Gambar 6. Grafik Kontur permukaan konversi vs Suhu dan rasio F/ C

Berdasarkan tinjauan thermodinamika, reaksi dasar polimerisasi pada pembentukan resin phenol formaldehid bersifat eksotermis (Othmer, 1984). Reaksi yang bersifat demikian akan mempunyai konversi yang lebih besar pada suhu rendah (Billmeyyer, 1957) dan mencapai konversi optimum pada suhu 75-85 ${ }^{\circ} \mathrm{C}$.

Sedangkan pada rentang suhu yang telah ditentukan, kenaikan rasio F/C akan meningkatkan konversi. Kenaikan rasio F/ Cakan meningkatkan jumlah formaldehid di dalam campuran reaksi sehingga jumlah phenol di dalam CNSL yang bereaksi dengan formaldehid semakin banyak atau konversi semakin meningkat. Tetapi ketika telah mencapai rasio F/ C optimum $(0,75)$, kenaikan rasio $\mathrm{F} / \mathrm{C}$ akan menurunkan konversi reaksi. Di atas rasio $\mathrm{F} / \mathrm{C}$ optimum, kenaikan rasio $\mathrm{F} / \mathrm{C}$ akan meningkatkan formaldehid dan menurunkan phenol sehingga jumlah molekul phenol di dalam campuran reaksi semakin menurun dan berdampak pada menurunnya konversi reaksi. Polimer-polimer jaringan terbentuk karena phenol yang merupakan gugus polifungsional. Dalam medium asam pembentukan eter berjalan cepat dikarenakan protonasi gugus-gugus alkohol oleh proton phenol atau oleh proton dari asam tambahan yang menyebabkan gugus tersebut jauh lebih rentan terhadap reaksi pergantian $\mathrm{S}_{\mathrm{N}} 1$ atau $\mathrm{S}_{\mathrm{N}} 2$ oleh gugus alkohol tetangganya. Apabila rasio terus dinaikkan melewati rentang optimumnya yakni F/C 0,65-0,85 maka akan membentuk metida-metida kuinon orto atau para yang reaktif yang menjadikan gugus akhir oligomer phenol formaldehid akan berikatan dengan formaldehid (Malcolm, 2001).

Resin phenol formaldehid yang terbentuk dari berbagai perbandingan formaldehid/ CNSL diamati secara visual dan hasilnya ditampilkan pada Tabel 2.

Resin yang diperoleh memadat setelah kering. Setelah dilakukan pemanasan, resin-resin yang memadat mengalami pelelehan. Dari fenomena tersebut, dapat disimpulkan bahwa resin yang diperoleh adalah jenis termoplast (novolak). Resin ini terbentuk dalam suasana asam di mana pembentukan gugus methylol lambat sedangkan pembentukan methylene cepat.

Sebelum mengering, resin novolak yang dihasilkan berbentuk cairan yang mempunyai berat molekul tertentu. Semakin besar berat molekul, semakin meningkat viskositas/ kekentalan produk dan semakin kuat daya adhesinya/daya rekatnya. Kadar resin terbesar pada perbandingan reaktan $\mathrm{F} / \mathrm{C}=0,75 / 1$ berbentuk cairan sangat kental dan mempunyai kelengketan yang paling baik serta memadat setelah kering. 
Tabel 2. Pengaruh rasio CNSL/ formalin terhadap bentuk resin

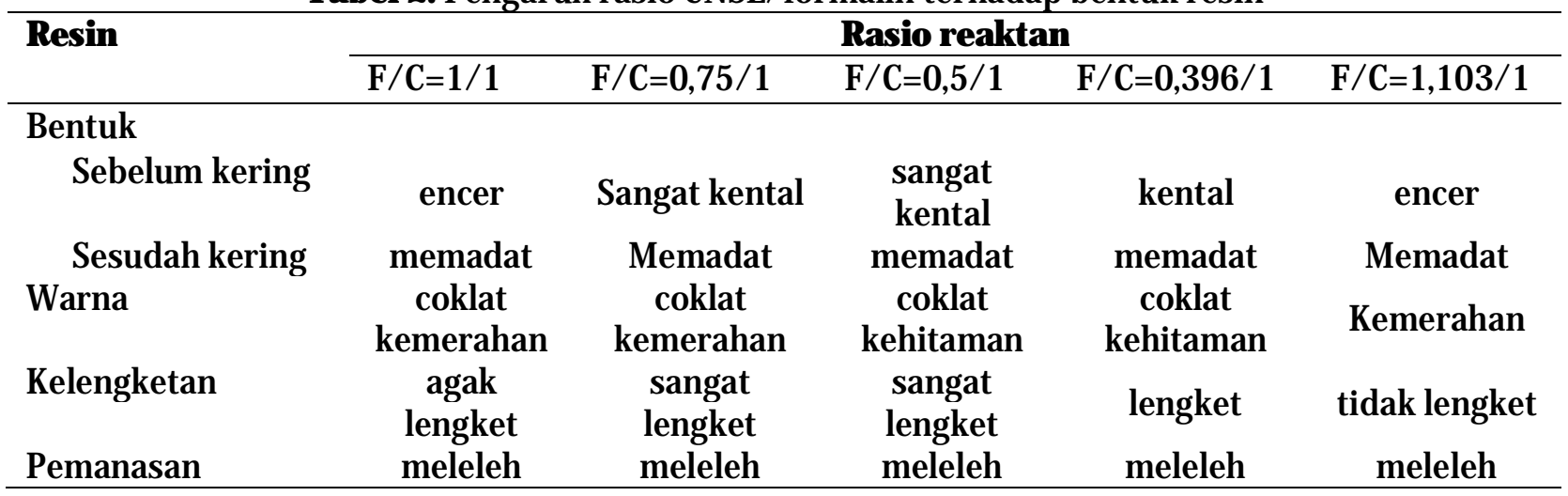

\section{KESIMPULAN}

Berdasarkan pengolahan data yang diperoleh dapat disimpulkan bahwa variabel yang paling berpengaruh adalah rasio formaldehid/ CNSL dan kondisi operasi optimum pada rentang rasio $\mathrm{F} / \mathrm{C}=0,65-0,85$ dan rentang suhu $75-85^{\circ} \mathrm{C}$ dengan konversi 0,55 . Kadar resin terbesar pada perbandingan $\mathrm{F} / \mathrm{C}=0,75 / 1$ yang berbentuk cairan sangat kental dan mempunyai kelengketan paling baik serta memadat setelah kering. Aplikasi resin phenol formladehid yang diperoleh menghasilkan kelengketan yang baik dengan warna cokelat kemerahan. Sedangkan pada variabel yang lain, coating yang dihasilkan mempunyai kelengketan yang kurang baik dengan warna cokelat kehitaman.

\section{UCAPANTERIMA KASIH}

Ucapan terima kasih disampaikan kepada Moch. Rizal Aulia dan M. Imam Baihaqi yang telah membantu pelaksanaan penelitian ini.

\section{DAFTAR PUSTAKA}

BPS, 2003, Statistika Indonesia.

Billmeyyer Jr, F.W., 1957, Textbook of Polymer Chemistry, Interscience Publisher INC, New York

Budiati, T., Cholies, N.Z. dan Soedigdo, S., 2004, Sintesis Metil Anakardat dan Uji Aktivitasnya sebagai Inhibitor Enzim Sulfhidril, BP, Vol. 6, No. 2

Daru, M. dan Nunung, M.D., 1994, Jambu Mete dan Pembudidayaannya, Penerbit Kanisius, Yogyakarta

Frisch, K.C., 1967, Phenolic Resin and Plastics dalam Kirk Othmer Encyclopedia of Chemical Technology, Vol. 15 Edisi 2, Mei Ya Publication Inc

Hesse, W., 1991, Phenolic Resin dalam Ulmann's Encyclopedia of Industrial Chemistry, Vol. 19 Edisi 5, VCH Publishers, New York

Malcolm, P. S., 2001, Kimia Polymer, Jakarta, PT. Pradnya Paramitha diterjemahkan oleh Iis Sopyan

Montgomery D.C., 2001, Design and Analysis of Experiments, John Wiley \& Sons, Inc., New York

Othmer, K., 1984, Encyclopedia of Chemical Technology, $3^{\text {rd }}$ edition, Interscience Publication, John Willey and Sons, New Yor 